\title{
ANTITUSSIVE EFFECT OF A PECTIC ARABINOGALACTANS ISOLATED FROM ADHATODA VASICA IN VIVO EXPERIMENTAL CONDITIONS
}

\author{
Fleskova D., ${ }^{1}$ Nosalova G., ${ }^{1}$ Saha Sudipta ${ }^{2}$, Bandyopadhyay Shruti ${ }^{2}$, Bimalendu Ray ${ }^{2}$, \\ Jurecek L. ${ }^{1}$
}

${ }^{1}$ Department of Pharmacology, Jessenius Faculty of Medicine, Comenius University, Martin
${ }^{2}$ Natural Products Laboratory, Department of Chemistry, The University of Burdwan, India

\begin{abstract}
The herbal polysaccharides have been the subject of many studies for a very long time, especially because of their physical properties, chemical and physical modification and application. Adhatoda vasica has also been traditionally included in preparations for the relief of cough, asthma and bronchitis recommended by Ayurvedic physicians for the management of various types of respiratory disorders. In this study, we have focused on activities of pectic arabinogalactans isolated from Adhatoda vasica on experimentally induced cough reflex and the changes of specific airway resistance in vivo conditions. The substance from leaves of Adhatoda vasica was marked as P-601 and the substance from stem bark of this shrub as P-602. The aim of presented study was to compare the antitussive activity of isolated arabinogalactans with cough suppressive activity of codeine („positive“ control) and effect acquired after application of water for injection (,negative“ control). Conscious male Trik guinea pigs (200-350g) were exposed to citric acid aerosol. Peroral administration of these substances in a dose of $50 \mathrm{mg}^{\mathrm{kg}} \mathrm{kg}^{-1}$ body weight decreased the number of citric acid induced cough efforts in guinea pigs more effectively than codeine. They did not induce any significant changes in the values of specific airway resistance and did not provoke any observable adverse effects.Our test results confirmed that polysaccharides isolated from Adhatoda vasica in vivo conditions have expressive antitussive effect compared with the oldest and the most effective cough suppressive agent - the codeine. The positive thing is the studied substances, despite strong supressive activity, did not induced any adverse side effects.
\end{abstract}

Key words: cough reflex, herbal polysaccharides, arabinogalactan, Adhatoda vasica

\section{INTRODUCTION}

Topicality of the research in this area is based on the fact that cough is the most common symptom for which patients seek medical care of doctor for the first contact or specialist pneumologist (1). Cough is an indispensable physiological reflex that helps to clean the respiratory tract from secretions, bacteria, cellular waste products and foreign materials when ciliary activity of the respiratory tract is inadequate. That means the cough protects the respiratory tract mucosa from potential sources of obstruction or irritation. Basis for coughing is receptor activation by mechanically, chemically, inflammatory processes or aeroallergens. Cough receptors are located under the mucous membranes of the respiratory system transferred to the bronchioles. They are concentrated in the carina, tracheal bifurcation, and its rear wall. For the cough receptors are considered especially afferent myelinated A fibers known as RARS (rapidly adapting receptors). Stimulation of RARS clearly initiates cough reflex (2). However, cough can also be induced by stimulation of nonmyelinated $\mathrm{C}$ fibers. It is assumed that while receptors of afferent myelinated A fibers involved in the formation of cough directly, the role of receptors of afferent nonmyelinated $\mathrm{C}$ fibers is indirect (3). The individual parts of reflex arc are subordinated to the anatomical and functional changes during the chronic respiratory diseases. The result of these changes is an inadequate excessive response. Cough becomes pathological, loses its protective function, causes discomfort to the sick, reduces quality of life and moreover, may also lead to life-threat-

Address for correspondence:

Fleskova D., Department of Pharmacology, JFM CU, Sklabinska Str. N. 26, 03601 Martin, Slovakia.

Tel: +421432633603; e-mail: d.fleskova@yahoo.co.uk 
ening complications (4). The most effective long-term antitussives used in the treatment of cough, act on central level. Their disadvantages include a huge number of adverse side effects (5). As the most hopeful appear to be herbal substances, which is assumed to lower incidence of adverse effects. For antitussive and expectorant effect of plants are responsible plant alkaloids, flavonoids, saponins, terpenoids, polysaccharides and other bioactive substances. Plant polysaccharides create on the contact surface protective layer, which reduces the irritation of cough receptors and vagal nerve endings leading to decrease in the parameters used for assessment of cough reflex (6). In this study we have focused on activities of peptic arabinogalactan isolated from Adhatoda vasica.

Arabinogalactan - proteins (AGPs) are found in most higher plants. Although the physiological functions of AGPs have not yet been identified, some evidence is found that they are involved in plant reproductive development, pattern formation and somatic embryogenesis. In general the arabinogalactan moiety of AGPs represents $90 \%$ of the weight, while the protein moiety represents $10 \%$ of the weight. Type I arabinogalactan consists of long -(1 4)linked D-galactopyranose (D-Galp) backbones substituted with short -linked and -linked L-arabinofuranose (L-Araf) side chains. The arabinogalactan moiety is characterized as a type II arabinogalactan consisting of a (1 3)- -D-galactan core branched at O-6 with (1 6)linked galactan outer chains heavily substituted with terminal -L-arabinofuranosyl residues. The protein moiety was found to be rich in the amino acids hydroxyprolin, serin, alanin, threonin, and glycin and although also AGPs have been characterized with different amino acid compositions (7).

Mechanism of cough suppressive effect is probably identic with the action of the herbal mucilages, while we know that they are able to create a protective layer of mucous membranes, especially in viral diseases of upper respiratory tract, leading to reduced stimulation of cough receptors (8).

Adhatoda vasica is an evergreen shrub and a medicinal plant which is a home remedy for several diseases and human requirements. It is mentioned in Vedas as a herbal remedy for treating cold, cough, whooping cough and chronic bronchitis and asthma, as sedative expectorant, antispasmodic and anthelmintic. It is an official drug and is mentioned in the Pharmacopoeia of India (1966). The drug is employed in different forms such as fresh juice, decoction, infusion and powder; also given as alcoholic extract and liquid extract or syrup. The leaves and roots contain alkaloids, vasicinone, vasicinolone and vasicol, which may have a bronchodilatory effect of the bronchii $(9,10)$.

\section{MATERIAL AND METHODS}

\section{Plant material}

Leaves of A. vasica were collected from the garden of medicinal plants, The University of Burdwan, West Bengal, India. Collected. leaves (10 g) were washed thoroughly with tap water and then blended with water $(800 \mathrm{ml}$ ) in a mixer (Waring Products, Inc., Torrington, CT, USA) (11). Extraction of polysacharides, isolation of arabinogalactan proteins and chemical analysis were described by Chattopadhyay et. al. (11).

\section{Animals}

The experiments were carried out on the conscious male Trik guinea pigs weighing 200$350 \mathrm{~g}$. The animals were obtained from the Department of Experimental Pharmacology, Slovak Academy of Science, Dobra Voda, Slovakia and located in faculty animal house. Guinea pigs were kept in the animal house with standard air conditioning system. All animals had a free access to water and food. They were adapted in quarantine to our conditions during several days. Experiments using animals were performed in accordance with the local Ethical Comittee at Jessenius Faculty of Medicine, Comenius University in Martin. 
Each of polysaccharides as well as codeine („positive“ control) and aqua pro injectione („negative“ control) were tested on individual group of animal consisting of 6-8 guinea pigs. Conscious animals were individually placed in a double chambers bodyplethysmograph box for laboratory animals (HSEtype 855, Hugo Sachs Elektronik, Germany) consisting of head and body chambers. The nasal airflow was registered in head chamber and the thoracic airflow in body chamber. The value of specific airway resistance is proportional to phase difference between nasal and thoracic respiratory airflow.

Aerosols were generated with an ultrasonic nebuliser. The plant substances were applied to guinea pigs perorally in the dose of $50 \mathrm{mg} \cdot \mathrm{kg}^{-1} \mathrm{~b} . \mathrm{w}$. The cough reflex was evoked by citric acid in a concentration 0,3M. The citric acid aerosol was produced by a jet nebulizer (PARI jet nebulizer, Paul Ritzau, Pari-Werk, Germany, output $5 \mathrm{~L} / \mathrm{s}$, particles mass median diameter $1.2 \mathrm{~m}$ ) and provided to the head chamber of the plethysmograph in 3 min intervals. During the exposure, the animal was continuously observed by two trained observers that evaluate the cough response objectively. Two observers analyzed typical cough responses and counted number of cough efforts. The citric acid induced cough and specific airway resistance were registered without any agent application and after that in 30, 60, 120 and 300 min intervals. Between measurements was observed 2 hours break for adapt cough receptors.

The reactivity of the airway smooth muscle in vivo conditions was expressed as values of specific airways resistance calculated according Pennock et al. by time difference between pressure changes in head and chest parts of bodypletysmograph during normal breathing pattern. After finishing the experiments, animals were monitored for $10 \mathrm{~min}$ and subsequently carried away to the animal house.

\section{Statistical analysis}

Data from the cough studies are expressed in total number of coughs. Data were evaluated using an unpaired Student t-test. All data were shown as mean \pm standard error of the mean (SEM). Significance of $\mathrm{p}<0.05, \mathrm{p}<0.01, \mathrm{p}<0.001$ is shown by one, two and three asterisks (*).

\section{RESULTS}

The effect of pectic arabinogalactans from A. vasica was evaluated on the citric acidinduced cough reflex and reactivity of airways smooth muscle in vivo conditions. For comparative purposes, codeine was simultaneously assayed as known reference compound. The results of antitussive test showed that peroral administration of the subtance P-601 in a dose 50mg. $\mathrm{kg}^{-1}$ body weight brought about a significant decrease in the number of citric acid induced cough efforts (NE) in adult healthy awaken guinea-pigs (Fig. 1). The first statistically significant result within $30 \mathrm{~min}$ after application was observed. Furthermore, this positive effect was observed during all the study time intervals. Notably, the suppression of cough efforts by the polymer was quantitatively that of codeine apllied in a dose $10 \mathrm{mg} \cdot \mathrm{kg}^{-1}$.

Airway resistance is a concept used in respiratory physiology to describe mechanical factors which limit the access of inspired air to the pulmonary alveoli, and thus determine airflow. It is dictated by, inter alia, the diameter of the airways. At present the relationship between cough and bronchoconstriction is not known with certainty. Although it is generally accepted that bronchodilating substances can cause cough suppression. Therefore, we have evaluated the changes of specific airway resistance as indicator of this activity. Our result suggests that the application of substance P-601 from A. vasica in the dose which provoked cough suppressive activities did not significantly change the values of specific airway resistance (Fig. 2). 


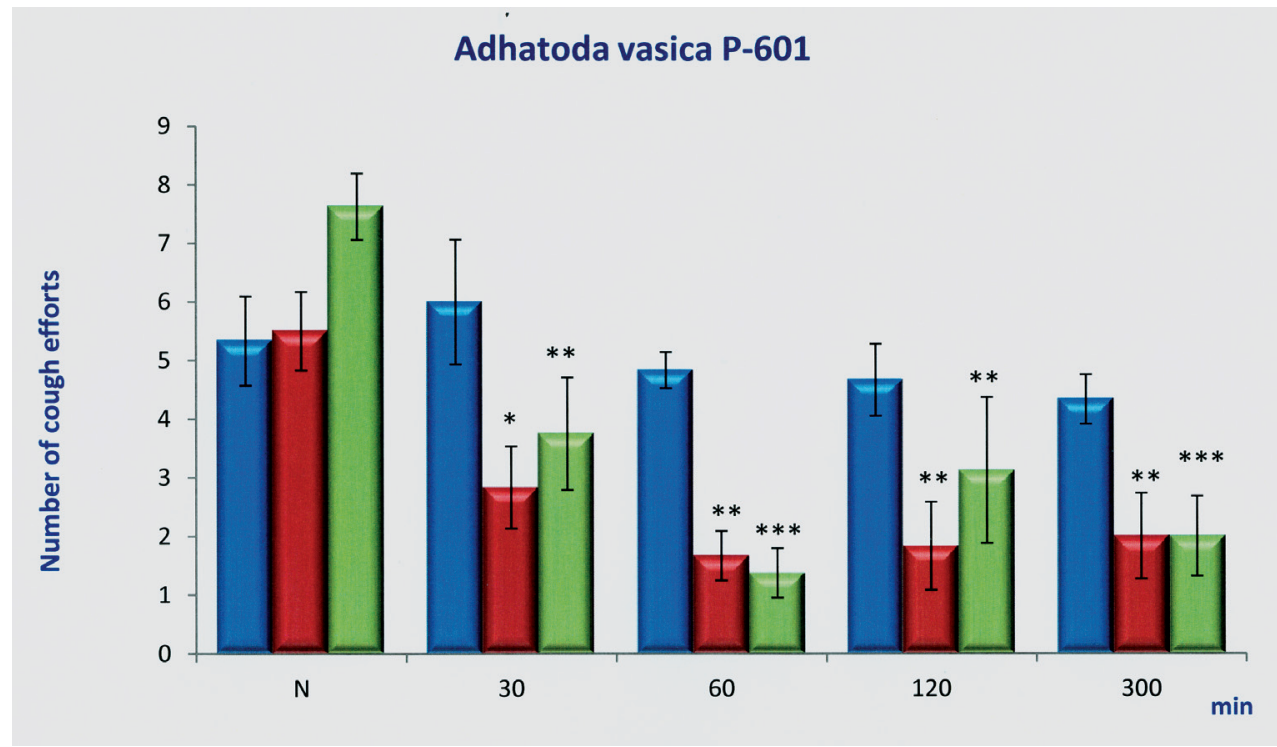

Fig. 1. The influence of the pectic arabinogalactan P-601 from Adhatoda vasica, codeine (,positive control“) and water for injection („negative“ control) on the citric acid-induced cough efforts (NE) in guinea-pigs recorded at 30 , 60, 120 and $300 \mathrm{~min}$ time intervals. All used substances were applied by peroral route of administration: plant polysaccharides in the dose of $50 \mathrm{mg} . \mathrm{kg}^{-1}$, codeine in the dose $10 \mathrm{mg} \cdot \mathrm{kg}^{-1}$ and water for injection in the dose $2 \mathrm{ml} . \mathrm{kg}$ ${ }^{1}$ body weight. N, initial values before application of the polysaccharides and codeine. Statistical significance is marked by asterisks ${ }^{* * *} \mathrm{p}<0.001 ;{ }^{* *} \mathrm{p}<0.01 ;{ }^{*} \mathrm{p}<0.05$.

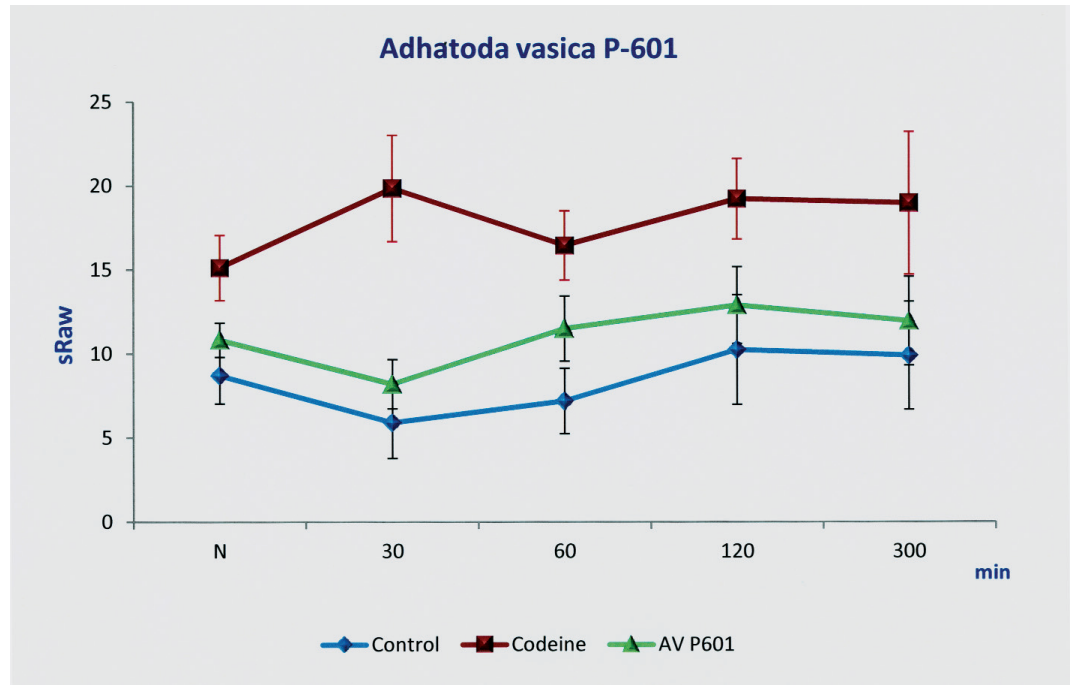

Fig. 2. The influence of a polysaccharide P-601 from the medicinal plant Adhatoda vasica and control agents (water for injection and codeine) on citric acid induced changes of specific airway resistance (sRaw) in vivo conditions, registered before any agent application (values labelled as $\mathrm{N}$ in graphs) and after that in 30, 60, 120 and 300 min time intervals.

Similarly, substance P-602 significantly decreased the number of cough efforts. Suppressive effect was shown after $30 \mathrm{~min}$. of polysaccharide solution application and persisted until the end of the experiment, up to $300 \mathrm{~min}$. from its application. Even in this 
experiment, the substance P-602 in some intervals exceeded the effect of codeine (Fig. 3). The results of our experiments have shown that substance P-602 did not influence the reactivity of respiratory smooth muscle (Fig. 4). Negative control - water for injections, that were applied at a dose of $2 \mathrm{ml} \cdot \mathrm{kg}^{-1}$ body weight did not influence the number of cough efforts and the values of specific airway resistance.

On the figure 5 is expressed as percentage the antitussive effect of codeine, A. vasica P601 and A. vasica P-602. There can be seen only minimal differences of suppressive effect in both applied polysaccharides compare to codeine.

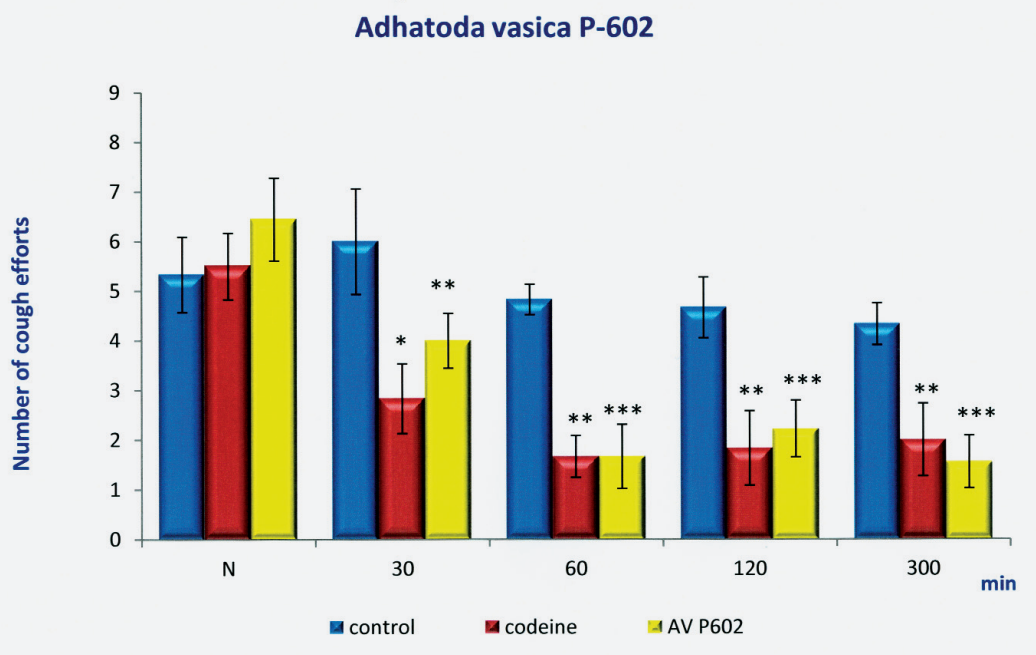

Fig. 3. The influence of the pectic arabinogalactan P-602, codeine (,positive control“) and water for injection („negative" control) on the citric acid-induced cough efforts (NE) in guinea-pigs recorded at 30,60, 120 and $300 \mathrm{~min}$ time intervals. All used substances were applied by peroral route of administration: plant polysaccharides in the dose of 50mg. $\mathrm{kg}^{-1}$, codeine in the dose $10 \mathrm{mg} \cdot \mathrm{kg}^{-1}$ and water for injection in the dose $2 \mathrm{ml} . \mathrm{kg}^{-1}$ body weight. N, initial values before application of the polysaccharides and codeine. Statistical significance is marked by asterisks ${ }^{* * *} \mathrm{p}<0.001 ;{ }^{* *} \mathrm{p}<0.01 ;{ }^{*} \mathrm{p}<0.05$

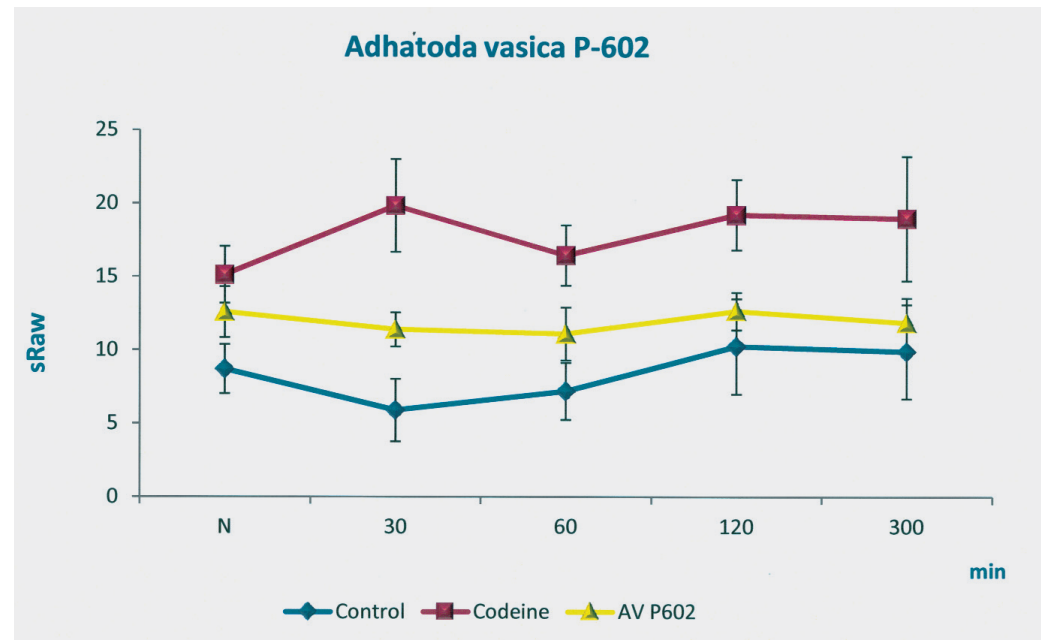

Fig. 4. The influence of a polysaccharide P-602 and control agents (water for injection and codeine) on citric acid induced changes of specific airway resistance (sRaw) in vivo conditions, registered before any agent application (values labelled as $\mathrm{N}$ in graphs) and after that in 30,60,120 and 300 min time intervals. 


\section{Antitussive effect expressed as \%}

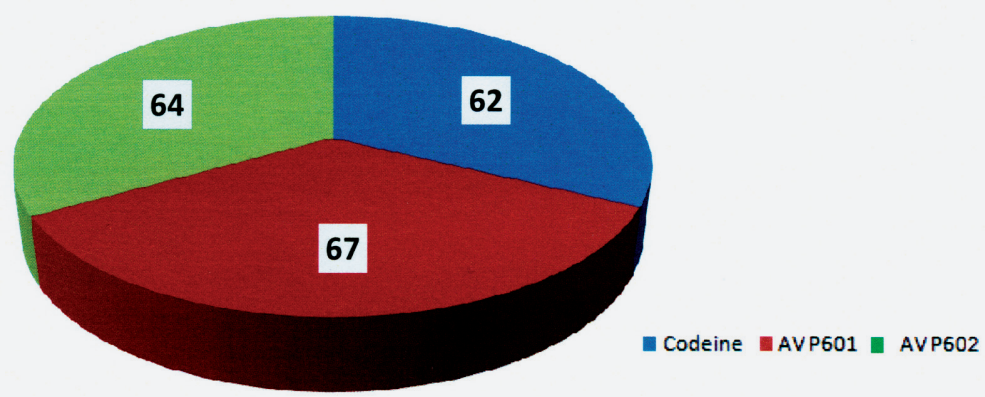

Fig. 5. Antitussive effect of codeine, Adhatoda vasica P-601 and Adhatoda vasica P-602 expressed as percentage.

\section{DISCUSSION}

The antitussives from the group of narcotic analgesics are widely used in clinical conditions. Their cough-suppresive effect is very strong in doses below those required for pain relief. Although, they are associated with relatively high adverse effects such as depression of the respiratory centre, decreased mucus secretion in bronchioles, as well as ciliary activity (12). All of these facts compel us to look for other non-narcotic substances preventing the pathological cough (13).

The herbal polysaccharides have been the subject of many studies for a very long time, especially because of their physical properties, chemical and physical modification and application $(14,15)$. Several works realized in our conditions have shown that plant polysaccharides could represent an effective alternative to synthetic drugs, because they decreased the parameters of mechanically and chemically induced cough reflex comparatively or even more in comparison with efficacy of peripheral antitussives (15). Presented results of our experiments also confirmed these facts. These findings clearly indicate that the polysaccharides isolated from Adhatoda vasica in vivo conditions have a significant antitussive effect comparable to the oldest and most active cough suppressive substance - codeine. We also found out that the polysaccharides applied in experimental animals did not induce any adverse side effects, which we consider to be positive in comparison to codeine. The mechanism by which plant polysaccharides influence experimentally induced cough reflex is not yet fully understood. We assume that observed cough suppressive effect of plant polysaccharides Adhatoda vasica may be associated with their ability to increase production of mucus in the airways, whether direct or indirect effects (via vago-vagal reflex). Increased production of mucus may hamper the access of irritating stimulus to airway mucosa. It is known that many plant polysaccharides, including those observed in our study, suppress experimentally induced cough reflex through this so-called barrier mechanism. In addition to increasing the secretion of mucus in the airways may the application of plant polysaccharides influence the nerve endings in epipharynx. Important is their ability to increase production of saliva. Hypersalivation subsequently leads to activation of swallowing reflex, which together with the cough reflex shared some central coordination mechanisms (16-19). Similarly, these facts can be applied in our observed suppression of cough after treatment of polysaccharide Adhatoda vasica.

The other mechanism of antitussive activity of our pectic arabinogalactans may be associated with an antispasmodic action or bronchodilator of many antitussive herbs $(20,21)$. They cause bronchial muscle relaxation in vitro, or decrease airways resistance in vivo. The arabinogalactan of present study possesses very high cough suppressive effect and decreas- 
es the values of specific airway resistance in vivo conditions only slightly. Pavord (22) reported that bronchoconstriction causes or enhances the sensitivity of cough, while bronchodilation does the opposite. However, the role of other mechanism including bioadhesive effect of the polysaccharide to the epithelial mucosa (23) cannot be ruled out. Further research should be directed in this area.

\section{REFERENCES}

1. Irwin SR, Madison MJ. The Diagnosis and Treatment of Cough. The New England Journal of Medicine 2000; 343: 1715-21.

2. Nosalova G, Mokry J, Franova S. Pharmacological modulation of coul reflex. In: Khan MTH and Ather A, editors. Leas Molecules from Natural Products. Elsevier 2006; 2: 87-110.

3. Lee YL, Pissari TE. Afferent properties and reflex functions of bronchopulmonary C-fibres. Resp Physiol 2001; 125: 47-65.

4. Nosalova G, Franova S, Mokry J, Sutovska M. Pharmacotherapy of cough. In: Korpas J, Paintal S, Anand A, editors. Cough from Lab to Clinic. Ane Books India 2006; 271-333.

5. Heinrich M, Barnes J, Gibbons S, Williamson EM. Fundamentals of Pharmacognosy and Phytotherapy. New York: Churchill Livingstone 2004; ISBN 0443071322.

6. Kostalova D, Kardosova A, Hajnicka V. Effect of Mahonia aquifolium stem bark crude extract and one of its polysacharide component on production of IL-8. Fitoterapia 2001; 72: 802-806

7. Oosterveld A, Voragen AGJ, Schols HA. Characterization of hop pectins shows the presence of an arabinogalactan - protein. Carbohydrate Polymers 2002; 49 (4), 407-413.

8. Nosalova G, Strapkova A, Kardosova A, Capek P, Zathurecky L, Bukovska E. Antitussive action of extracts and polysaccharides of marshmallow (Althaea officinalis L., var. Robusta). Pharmazie 1992; 47: 224-226.

9. Jagangir T, Khan TH, Prasad L, Sultana S. Reversal of Cadmin Chloride-Induced Oxidative Stress and Genotoxicity by Adhatoda vasica Extract in Swiss Albino Mice. Biological Trace Element Research 2007; 111 (1-3): 217-228.

10. Dhuley JN. Antitussive Effect of Adhatoda vasica Extract on Mechanical or Chemical Stimulation-Induced Coughing in Animals. J. Ethnopharmacol 1999; 67(3): 361-365.

11. Chattopadhyay N, Nosalova G, Sahaa S, Bandyopadhyay SS, Fleskova D, Ray B. Structural features and antitussive activity of water extracted polysacharide from Adhatoda vasica. Carbohydrate Polymers 2011; 83 1970-1974.

12. Takahama K, Shirasaki T. Central and peripheral mechanisms of narcotic antitussives: codeine-sensitive and resistant coughs. Cough 2007; 3: 8.

13. Brown C, Fezoui M, Selig WM, Schwartz CE, Ellis JL. Antitussive activity of sigma - 1 receptor agonists in the guinea-pig. British J Pharm 2004; 141: 233 - 240.

14. Paulsen BS, Barsett H. Bioactive pectic polysaccharides. In: Heinze T, Klemm D, editors. Polysachcarides I Structure, Characterization and Use Advances in Polymer Science. Springer 2005; p. 186: 281.

15. Diallo D, Baulsen BS, Liljebäck THA, Michaelsen TE. Polysacharides from the roots of Entada africana Guill.at Perr., Mimosaceae, with complement fixing activity. J Ethnopharm 2001; 74: 159-171.

16. Nosalova G, Sutovska M, Mokry J, Kardosova A, Capek P, Khan THM. Efficacy of the herbal substances according to cough reflex. Minerva Biotechnologica 2005; 17: 141-152.

17. Nosalova G, Capek P, Sutovska M, Franova S, Matulova M. Antitussive Active Polysaccharides from Ornamental-Medicinal Plants. Floriculture. Ornamental and Plant Biotechnology 2006; 4: 471-480.

18. Šutovská M, Nosálová G, Fraňová S, Kardošová A. Isolation, characterization, and antitussive activity of polysaccharides from the flowers of Althaea officinalis L., var. Robusta. Leaves of Arcticum lappa L., var. Herkules, and gum exudate of peach tree (Prunus persica L., Batsch). Bratislavské Lekárske Listy 2007; 108: 93-99.

19. Broussard DL, Altschuler SM. Central integration of swallow and airway-protective reflexes. Am. J. Med 2000; 108 (4): $62-67$

20. Ernst E. Complementary therapies for asthma: What patient use? The Journal of Asthma: Official Journal of the Association for the Care of Asthma 1998; 35, 667-671.

21. Pavord I.M, Chung K F. Chronic cough: Treatment and management. Lancet 2008; 371, 1375-1384.

22. Pavord ID. Cough and asthma. Pulmonary Pharmacology \& Therapeutics 2004; 17, 399-402.

23. Šutovská M, Frañová S, Prisenžňáková L, Nosál'ová G, Togola A, Diallo D. Antitussive activity of polysaccharides isolated from the Malian medicinal plants. International Journal of Biological Macromolecules 2009; 44, 236-239.

Acknowledgements: This research was supported by grant LPP-0317-09 and APVV 0030-07 and the Center of Experimental and Clinical Respirology.

Received: Oct, 26, 2011

Accepted: Nov, 19, 2011 